Revista Verde de Agroecologia e Desenvolvimento Sustentável

http://www.gvaa.com.br/revista/index.php/RVADS

REVISÃO BIBLIOGRÁFICA

DOI: http://dx.doi.org/10.18378/rvads.v10i5.3636

\title{
Capacidade antioxidante de frutas e hortaliças
}

\section{Antioxidant capacity of fruits and vegetables}

\author{
Elga Batista da Silva ${ }^{1}$; Marcela Cristina Machado Raposo ${ }^{2}$; Michele Matias da Conceição ${ }^{3}$; Vanessa de Oliveira dos Santos $^{4}$
}

Resumo: A definição de alimentos funcionais ainda é controversa na literatura, são definidos como aqueles que apresentam concentrações de um ou mais ingredientes modificados ou manipulados para melhorar sua contribuição para dieta saudável. Esses alimentos apresentam ainda nutrientes em quantidades apreciáveis, como é o caso das frutas e hortaliças que apresentam em sua composição compostos antioxidantes capazes de combater os radicais livres. Objetivou-se com essa revisão bibliográfica discutir os benefícios dos compostos com atividade antioxidantes presentes em frutas e hortaliças. Este estudo se utilizou da revisão de literatura para buscar evidencias sobre o tema abordado. Os carotenoides formam uma classe de pigmentos presentes nos vegetais, além das propriedades biológicas envolvendo sua atividade antioxidante, destacarmos a função antioxidante dos compostos fenólicos e das vitaminas A, C e E. As vitaminas são substâncias orgânicas presentes em muitos alimentos em pequenas quantidades e essenciais para o bom funcionamento de muitos processos fisiológicos do corpo humano. $\mathrm{O}$ aumento do consumo de frutas e hortaliças deve ser estimulado, pois diversos compostos presentes na célula vegetal como visto no presente trabalho, dentre eles a função antioxidante das vitaminas $\mathrm{A}, \mathrm{C}$ e $\mathrm{E}$, desempenham proteção e redução do risco de diversas doenças.

Palavras-chave: Vitaminas antioxidantes; Carotenoides; Radicais livres; Compostos fenólicos.

\begin{abstract}
The definition of a functional food is still controversial in literature, they are defined as those having concentrations of ingredients one or more modified or manipulated to enhance their contribution to healthy diet. These foods still have appreciable amounts of nutrients, such as fruit and vegetables that have in their composition antioxidant compounds capable of combating free radicals. The aim of this review was to discuss benefits of compounds with antioxidant activity present in fruits and vegetables. This study used the literature review to seek evidence on the topic discussed. Carotenoids are a class of pigments present in plants, involving biological properties beyond its antioxidant activity, we deploy the antioxidant activity of the phenolic compounds and vitamins A, C and E. Vitamins are organic substances present in small amounts in many foods and essential for the proper functioning of many physiological processes of the human body. Increased consumption of fruits and vegetables should be encouraged, because many compounds present in the plant cell as seen in this study, including the antioxidant function of vitamins $\mathrm{A}, \mathrm{C}$ and $\mathrm{E}$ play an important role in protection of various diseases.
\end{abstract}

Key words: Antioxidant vitamins; carotenoids; Free radicals; Phenolic compounds.

\footnotetext{
*Autor para correspondência

Recebido para publicação em 12/09/2015; aprovado em 22/12/2015

${ }^{1}$ Docente da Unisuam (RJ) M.Sc. Ciência e Tecnologia de Alimentos (UFRRJ). E-mail: elga.silva@ hotmail.com

${ }^{2}$ Acadêmica de Nutrição, Faculdade Bezerra de Araújo, Itaguaí; (21)98108-5542, marcelamraposo@ gmail.com

${ }^{3}$ Acadêmica de Nutrição, Faculdade Bezerra de Araújo, Rio de Janeiro, michelematias2000@ yahoo.com.br

${ }^{4}$ Acadêmica de Nutrição, Faculdade Bezerra de Araújo, Rio de Janeiro, vanessadeoliveiranutricionista@gmail.com
} 


\section{INTRODUÇÃO}

A definição de alimentos funcionais ainda é controversa na literatura, visto que para a indústria esses alimentos são aqueles que além de vincular nutrientes, fornecem benefícios adicionais à saúde. Já para o U.S. Institute of Medicine de National Academy of Sciences dos EUA, alimentos funcionais são definidos como aqueles que apresentam concentrações de um ou mais ingredientes modificados ou manipulados para melhorar sua contribuição para dieta saudável. No Brasil, a Agência Nacional de Vigilância Sanitária (ANVISA), define que tratam-se de alimentos ou ingredientes que possuem propriedades funcionais ou de saúde podendo, além de funções nutricionais básicas, produzirem efeitos metabólicos e/ou fisiológicos e/ou efeitos benéficos à saúde, sendo seguros para consumo sem supervisão médica. Enfim, podem ser definidos como alimentos (in natura ou processados) que tem propriedades de reduzir o risco de enfermidades e, portanto, contribuir para a manutenção da saúde. (KATAN, 2009; BRASIL, 2008).

$\mathrm{O}$ termo alimento funcional foi inicialmente utilizado pelo governo do Japão, em meados de 1980, como resultado de esforços para desenvolver alimentos que possibilitassem a redução dos gastos com a saúde pública, levando em consideração a elevada expectativa de vida naquele país. Além disso, é válido ressaltar que o Japão foi o pioneiro na formulação do processo de regulamentação específica para esta categoria de alimentos (ARABBI, 2001; PIMENTEL, FRANCKI; GOLLUCKE, 2005; STRINGHETA et al., 2007).

Considerando-se os benefícios de ordem nutricional desse tipo de alimento, a dieta baseada em alimentos funcionais constitui uma estratégia para promover saúde e bem estar ao ser humano. Esses alimentos apresentam ainda nutrientes em quantidades apreciáveis, como é o caso das frutas e hortaliças que apresentam em sua composição compostos antioxidantes capazes de combater os radicais livres, prevenindo assim o desenvolvimento de doenças e retardando o envelhecimento (COLLA; MORAES, 2006; SUCUPIRA et al., 2012).

Os radicais livres são moléculas formadas normalmente durante a respiração e a digestão de alimentos e podem causar danos às células e levar a diversas doenças graves, como aterosclerose e câncer. São instáveis, pois seus átomos possuem um número ímpar de elétrons, necessitando atingir a estabilidade através da obtenção de elétrons de outros componentes. Entretanto, cada vez que uma proteína ou um lipídeo perde um elétron, essas biomoléculas sofrem transformações irreversíveis na forma e na função e pela perda de um elétron, torna-se um novo radical livre, e, portanto, uma espécie de reação em cadeia. Assim, os antioxidantes têm a função de proteger o organismo combatendo a ação danosa dos radicais livres. Alguns antioxidantes são produzidos pelo próprio corpo e outros (como as vitaminas $\mathrm{C}$ e $\mathrm{E}$, o beta-caroteno, o selênio, alguns aminoácidos e o zinco) precisam ser ingeridos (PIENIZ, 2009; BONI et al., 2010).

Nos anos recentes, a produção e o consumo de frutas e hortaliças têm crescido provavelmente devido a evidências de compostos antioxidantes presente nos mesmos, tais como os carotenoides: licopeno, xantina, beta-caroteno, luteína, zeaxantina e astaxantina. "O consumo de frutas não é simplesmente uma preferência entre os consumidores, pois se tornou uma preocupação de saúde, devido à presença de nutrientes importantes nessas matérias primas" (SUCUPIRA, 2012). Os antioxidantes são moléculas capazes de inibir a oxidação, minimizando a quantidade de radicais livres (PIENIZ, 2009).

Os carotenoides são substâncias (pigmentos naturais) presentes nas células vegetais, importantes para sua coloração. Alguns desses pigmentos são precursores da vitamina A (como licopeno, xantina, beta-caroteno, luteína, criptoxantina, zeaxantina e astaxantina), além de possuírem atividade antioxidante devido a sua capacidade de oxidar os radicais de oxigênio, sendo, portanto, importantes inativadores dessas moléculas. Além de desempenharem função lipofílica, os carotenoides atuam como antioxidantes de lipoproteínas (VALDUGA, 2009).

Encontra-se também nos tecidos vegetais as substâncias fenólicas, que são produtos do metabolismo secundário das plantas, podendo ser encontradas de forma livre ou ligadas a açúcares e proteínas. Essas apresentam propriedade antioxidante devido sua ação de oxi-redução, as quais desempenham função na neutralização de radicais livres (SILVA, 2010).

Nesse sentido, Boni et al. (2010) destacam que as vitaminas $\mathrm{A}, \mathrm{C}$ e $\mathrm{E}$ possuem função antioxidante, pois conferem proteção contra a oxidação das células, com capacidade de se reduzirem. Essa função pode ser mensurada por meio de observações da concentração de lipídeos e da gênese das doenças cardiovasculares.

Objetivou-se com essa revisão bibliográfica discutir os benefícios dos compostos com atividade antioxidantes presentes em frutas e hortaliças.

\section{METODOLOGIA}

Este estudo se utilizou da Revisão de Literatura para buscar evidencias sobre o tema abordado. Para a realização desta investigação, foram pesquisados os seguintes descritores: "atividade antioxidante", "frutas e hortaliças", "radicais livres", "vitaminas", "carotenoides", "compostos fenólicos", em função de buscar dados atuais sobre o benefício antioxidante de frutas e hortaliças. As referências bibliográficas dos artigos encontrados também foram utilizadas para localizar outros trabalhos que abordassem o tema em questão.

\section{REVISÃO}

\section{Carotenoides}

Carotenoides formam uma classe de pigmentos lipossolúveis presentes nos vegetais que incluem os carotenos (pigmentos amarelos ou alaranjados) e xantofilas (pigmentos amarelados), que são encontrados em organelas celulares como o cloroplasto e cromoplasto (JASWIR et al., 2011). Segundo Silva et al. (2010), os principais carotenoides encontrados em produtos vegetais são: beta-caroteno, luteína, zeaxantina e licopeno.

De acordo com Silva et al. (2010), uma ampla variedade de carotenoides são encontrados nos tecidos de plantas comestíveis e os exemplos mais comuns são: tomates, cenouras, milho, pimentas vermelhas, urucum, batata doce, 
abóbora, pimentão vermelho e amarelo, inhame, cará, azeitona roxa, repolho roxo, folhas verde-escuras (como brócolis e espinafre), alface, aipo, maçã, damasco, manga, ameixa, frutas vermelhas, melancia, laranja, tangerina, nectarina e mamão.

O interesse pelos carotenoides tem aumentado nos últimos anos devido à descoberta de propriedades biológicas envolvendo sua atividade antioxidante, através do sequestro e eliminação de radicais livres, reduzindo com isso o risco do desenvolvimento de doenças degenerativas como o câncer, doenças cardiovasculares, imunodeficiências, degeneração macular, formação de cataratas e benefícios relacionados ao processo de envelhecimento (RIOS, 2009; DAMODARAN et al., 2008 apud SILVA et al., 2010).

O beta-caroteno é encontrado na cenoura, abóbora, manga e mamão, e é a principal fonte de próvitamina A da dieta humana (RAVEN et al, 2001). As baixas concentrações de desse pigmento no plasma aumentam significativamente a incidência de infarto do miocárdio; enquanto que uma dieta rica do pigmento é associada ao menor risco de morte prematura devido às doenças coronarianas (STREET et al., 1994; BELLIZI et al., 1994 apud SILVA et al., 2010). RIOS et al. (2009); JASWIR et al. (2011) relatam que o uso de betacaroteno diminui o risco de câncer de pulmão, reto, pele e estômago.

As xantofilas possuem atividade provitamina A e sua baixa ingestão ou baixa concentração no plasma está associada à degeneração macular. Porém, em concentrações ideais, além de manter a saúde dos olhos, mantêm a saúde do coração por reduzirem os riscos de doenças cardiovasculares e ainda protegem a pele dos danos causados por radiação ultravioleta (MARINOVA; RIBAVORA, 2007).

O licopeno é o carotenoide predominante no plasma e nos tecidos humanos, sendo encontrado em um número limitado de alimentos de cor vermelha, como tomates, que são umas das fontes mais ricas desse pigmento, e seus produtos, goiaba, melancia, mamão e pitanga. Não tem atividade de provitamina $\mathrm{A}$, é lipossolúvel e possui, entre os carotenoides, a maior capacidade sequestrante do oxigênio singlete. Com isso, protege biomoléculas como lipídeos, proteínas, lipoproteínas de baixa densidade (LDL) e o DNA, e assim funciona como um antioxidante muito potente. Além disso, ele é capaz de reduzir a mutagênese e, em concentrações fisiológicas, pode inibir o crescimento de células humanas cancerígenas, especialmente em câncer de próstata, estômago e pulmão sem evidência de efeitos tóxicos ou apoptose celular (SCOLASTICI et al., 2007; SHAMI; MOREIRA, 2004; AGARWAL; RAO, 2000, FERRARONI, 1994, KUCUK et al., 2002 apud RIOS, 2009).

\section{Compostos fenólicos}

Os compostos fenólicos são estruturas químicas que apresentam hidroxilas e anéis aromáticos, nas formas simples ou de polímeros, que os confere o poder antioxidante. Esses compostos foram classificados em três categorias: pouco distribuídos na natureza, polímeros e largamente distribuídos na natureza (ANGELO; JORGE, 2007).

Nos compostos fenólicos pouco distribuídos na natureza, encontra-se um número bem reduzido, embora com certa frequência. Neste grupo estão os fenóis simples, o pirocatecol, a hidroquinona, resorcinol e os aldeídos derivados dos ácidos benzoicos, que são constituintes dos óleos essenciais, como a vanilina (SOARES, 2002).
$\mathrm{Na}$ categoria dos polímeros estão os taninos e as ligninas, compostos fenólicos que não se apresentam na forma livre nos tecidos vegetais. E nos compostos largamente distribuídos na natureza estão os fenólicos encontrados em praticamente todo reino vegetal. Esse grupo pode-se dividir em flavonoides (antocianinas, flavonois e seus derivados) e ácidos fenólicos (ácidos benzoico, cinâmico e seus derivados) e cumarinas (KING; YOUNG, 1999 apud ANGELO; JORGE, 2007).

Vários efeitos benéficos à saúde têm sido atribuídos aos compostos fenólicos presentes nas frutas, vegetais, chás e vinhos tintos. Estudos epidemiológicos, clínicos e in vitro mostram múltiplos efeitos biológicos relacionados aos compostos fenólicos da dieta, tais como: atividades antioxidante, antiinflamatória, antimicrobiana e anticarcinogênica (BEER et al., 2003; DELMAS et al., 2005). Adicionalmente, Hayek et al. (1997) relatam evidências de que a ingestão de flavonoides como a quercetina e a catequina está associada à redução da oxidação do LDL-colesterol e à redução da agregação plaquetária, contribuindo para a diminuição da progressão da lesão aterosclerótica.

Segundo Silva (2010), os compostos fenólicos agem como antioxidantes, não somente por sua habilidade em doar hidrogênio ou elétrons, mas também em virtude de seus radicais intermediários estáveis, que impedem a oxidação de vários ingredientes do alimento, particularmente de lipídios. Essa ação dificulta a formação de radicais livres no organismo e protege as moléculas de DNA, podendo inibir algumas fases dos processos carcinogênicos. A atividade anticarcinogênica dos fenólicos tem sido relacionada à inibição dos cânceres de cólon, esôfago, pulmão, fígado, mama e pele. Os compostos fenólicos que possuem este potencial são resveratrol, quercetina, ácido cafeico e flavonóis (PIMENTEL, 2005).

As principais fontes de compostos fenólicos são frutas cítricas, como limão, laranja e tangerina, além de outras frutas como a cereja, uva, ameixa, pêra, maçã e mamão, sendo encontradas em maiores quantidades na polpa que no suco dessas frutas, e ainda em fontes como pimenta verde, brócolis, repolho roxo, cebola, alho e tomate são excelentes fontes desses compostos (PIMENTEL, 2005).

\section{Vitaminas antioxidantes (A, C, E)}

As vitaminas são substâncias orgânicas presentes em muitos alimentos em pequenas quantidades e essenciais para o bom funcionamento de muitos processos fisiológicos do corpo humano. Cumprem papel importante no metabolismo celular e no crescimento, elas regulam e favorecem as reações químicas que ocorrem nas células, permitindo a assimilação dos alimentos (OLIVEIRA, 2007).

Para Dorfman (2012) os antioxidantes são estudados individualmente e em conjunto, visando prevenir os danos do tecido muscular. Os radicais livres são neutralizados por vitaminas com atividade antioxidantes, devido à manutenção da resposta imunológica ideal e redução da peroxidação lipídica.

As vitaminas são classificadas em dois grupos: lipossolúveis e hidrossolúveis, de acordo com propriedades fisiológicas e físicoquímicas comuns. As lipossolúveis são solúveis em solventes lipídicos, como as vitaminas A e E, e posteriormente necessitam de gordura para a absorção adequada e sendo excretadas geralmente com as fezes através da circulação êntero-hepática. Já as hidrossolúveis, como a 
vitamina C, solubilizam-se em meios aquosos e estão presentes em fontes vegetais. São considerados substratos e cofatores essenciais das enzimas envolvidas em várias ações do metabolismo. A maior parte das vitaminas hidrossolúveis não é armazenada no organismo e sua excreção é feita pelas vias urinárias (OLIVEIRA, 2007; GALLAGHER, 2012).

\section{Vitamina A}

A vitamina A (retinol) compreende um grupo de compostos alimentares essenciais lipossolúveis que são estruturalmente relacionados ao retinol (vitamina A préformada) e que compartilham atividades biológicas. Assim, são considerados vitamina A os carotenoides (principalmente o beta-caroteno) com atividade de provitamina A que atuam como precursores alimentares do retinol. Essa vitamina préformada é encontrada apenas em produtos alimentares de origem animal, enquanto que os carotenoides dietéticos estão presentes somente em frutas e hortaliças (CATANIA et al., 2009).

De acordo com Moreira (2007), a vitamina A é necessária para a integridade da fotorrecepção nas células da retina, propiciando a visão. Sua deficiência ocasiona a chamada cegueira noturna, além de ser essencial para o desenvolvimento e crescimento do esqueleto e das partes moles, por participar na diferenciação e na síntese proteica, da síntese dos linfócitos T. Adicionalmente, a vitamina A atua na espermatogênese e desempenha papel anticancerígeno, como descrito anteriormente, sendo apontadas propriedades da mesma na redução do risco de neoplasias das células ósseas; além de atuar no desenvolvimento e na manutenção do tecido epitelial. Já a carência desse nutriente causa a queratinização das mucosas dos tratos urinário, digestório e alimentar, interferindo na barreira à infecção, desempenhada por essas mucosas. As principais fontes de vitamina A são fígado, leite ovos, queijo, manteiga, frutas, jerimum, cenoura, pimentão, tomate, alface, banana-comprida, manga, mamão, entre outras.

Conforme Assis et al. (2002) foi realizado um ensaio clínico de base comunitária, aleatório e placebo controlado. A questão central foi avaliar o impacto da suplementação com vitamina A na redução da taxa da morbidade por diarreia e infecção respiratória, teve duração de 12 meses com 1.240 crianças pré-escolares residentes no Nordeste brasileiro. A amostra constituída tinha um poder de $90 \%$ e um de $5 \%$ para observar uma redução de $15 \%$ na taxa de incidência da diarreia.

Crianças de 6 a 48 meses foram alocadas nos grupos de tratamento. Uma cápsula de 200.000 UI de vitamina A (100.000 UI para as menores de 12 meses de idade) ou uma cápsula de placebo foram oferecidas às crianças a cada 4 meses, durante 1 ano. Dados de diarreia e infecção respiratória foram coletadas em dias alternados, durante todo estudo. Os resultados do estudo indicaram que, à medida que aumentava o número de dejeções/dia, as crianças suplementadas com vitamina A tiveram taxas de prevalência média de $8 \%, 10 \%, 20 \%$ e $23 \%$ mais baixas do que as taxas observadas nas crianças do grupo placebo. Conclui-se que, a suplementação com vitamina A exerce impacto positivo na redução da diarreia e mostra o efeito protetor da vitamina A na redução da severidade da diarreia em pré-escolares, e estes resultados somam-se àqueles que também detectaram diminuição da severidade da diarreia nas crianças suplementadas e com algumas meta-análises, que reportam a redução de 29 a $39 \%$ na incidência da diarreia quando comparada com a identificada nas crianças do grupo placebo.

\section{Vitamina C}

A vitamina $\mathrm{C}$ ou ácido ascórbico (AA) é um nutriente hidrossolúvel e termolábil. Sendo considerado o antioxidante hidrossolúvel mais importante no organismo. Mais de $85 \%$ dessa substância é obtida a partir de frutas e hortaliças (LEE; KADER, 2000).

$\mathrm{O}$ ácido ascórbico tem a capacidade de eliminar diferentes espécies de radicais livres, tais como os radicais superóxido e hidroxil, além de reduzir radicais tocoferóis de volta para sua forma ativa nas membranas celulares, mantendo a sua integridade em células dos organismos aeróbios (KAUER; KAPOOR, 2001; NAIDU, 2003). Estudos indicam que o ácido ascórbico pode prevenir mutações em DNA de humanos, uma vez que altas concentrações do ácido reduzem mutações causadas por estresse oxidativo em células humanas in vitro (LUTSENKO et al., 2002).

A vitamina $\mathrm{C}$ é geralmente consumida em grandes doses pelos seres humanos, sendo adicionada a muitos produtos alimentares para inibir a formação de metabólitos nitrosos carcinogênicos. Os benefícios obtidos na utilização terapêutica do ácido ascórbico em ensaios biológicos com animais incluem o efeito protetor contra os danos causados pela exposição às radiações e medicamentos. Os estudos epidemiológicos também atribuem a essa vitamina um possível papel de proteção no desenvolvimento de tumores nos seres humanos. Contudo, a recomendação de suplementação dessa vitamina deve ser avaliada especificamente para cada caso, pois existem muitos componentes orgânicos e inorgânicos nas células que podem modular a atividade da vitamina $\mathrm{C}$, afetando sua ação antioxidante (BIANCHI; ANTUNES, 1999).

Em suma, pela grande facilidade de doar e receber elétrons, o ácido ascórbico: atua na produção e manutenção do colágeno; reduz a suscetibilidade à infecção; participa do processo de cicatrização; participa da síntese de serotonina; tem ação antioxidante, especialmente em conjunto com a vitamina E carotenoides; e causa efeitos sobre doenças respiratórias e reações alérgicas (FRANCESCHINI et al., 2012). Adicionalmente, Gallagher (2012) relata que a vitamina $\mathrm{C}$ promove a resistência à infecção por estar envolvido com a atividade imunológica dos leucócitos, a produção de interferon e o processo de reação inflamatória. Além disso, a ingestão de altas doses dessa substância reduz os sintomas dos resfriados, mas não os impede.

De acordo com Boni et al. (2010) as análises feitas com sete estudos do tipo coorte, que relacionaram a ingestão de vitaminas antioxidantes e a sua suplementação com as doenças cardiovasculares em adultos, mostrou que a suplementação de vitamina C (mediana de ingestão + suplementação de $756 \mathrm{mg} / \mathrm{dia}$ ) obteve resultado positivo quanto à prevenção de doença cardiovascular.

\section{Vitamina E}

A vitamina E é a principal vitamina lipossolúvel presente no plasma e na partícula de LDL. É um componente dos óleos vegetais encontrada na natureza em quatro formas diferentes: alfa, beta, gama e delta-tocoferol, sendo o alfatocoferol a forma antioxidante amplamente distribuída nos tecidos e no plasma. Os tocoferóis convertem radicais livres em espécies mais estáveis por meio da doação de um átomo 
de hidrogênio, gerando produtos eletricamente estáveis ou menos reativos (potencial antioxidante) (CATANIA et al., 2009). Segundo Bianchi e Antunes (1999) essa vitamina impede ou minimiza os danos provocados pelos radicais livres associados com doenças específicas, incluindo o câncer, artrite, catarata e o envelhecimento. De fato, os danos oxidativos podem ser inibidos pela ação antioxidante dessa vitamina, juntamente com a glutationa, a vitamina $\mathrm{C}$ e os carotenoides, constituindo um dos principais mecanismos da defesa endógena do organismo (BIANCHI; ANTUNES, 1999).

Segundo Skeaff (2009), a ação antioxidante é a principal propriedade química da vitamina $\mathrm{E}$, e sua ingestão importante para o combate de doenças ligadas às reações oxidativas, como cardiopatias, hipertensão, diabetes, obesidade e câncer. Adicionalmente, Gallagher (2012) relata que a deficiência de vitamina $\mathrm{E}$ causa danos no sistema neuromuscular, como prejuízo da sensação de posição e vibratória, alteração no equilíbrio e coordenação, fraqueza muscular e distúrbios visuais, no sistema vascular e reprodutor. Suas principais fontes E são os óleos vegetais, a manteiga, os ovos, as oleaginosas e algumas hortaliças.

Para Boni et al. (2010) diversos estudos demonstram os efeitos da ingestão de doses de vitamina $\mathrm{E}$ acima da atual recomendação, na forma de suplementos, na prevenção de doenças crônicas não-transmissíveis e no estímulo do sistema imune. Em contrapartida, Guinazi (2010) relata que a atual recomendação de vitamina E levaria em consideração a atuação dessa vitamina na prevenção de doenças relacionadas ao estresse oxidativo e que altas doses de vitamina E estariam associadas a um efeito pró-oxidantes.

\section{CONSIDERAÇÕES FINAIS}

Os compostos antioxidantes, encontrados em frutas e hortaliças, são substâncias de extrema importância para a manutenção do organismo conferindo proteção e benefícios à saúde. Desta forma, o aumento do consumo de frutas e hortaliças deve ser estimulado, pois diversos compostos presentes na célula vegetal como visto no presente trabalho, dentre eles a função antioxidante das vitaminas A, C e E, desempenham proteção e prevenção de diversas doenças, além de contribuírem para uma alimentação mais saudável e proporcionarem qualidade de vida.

\section{REFERÊNCIAS}

AGARWAL, S; RAO, A. V. Tomato lycopene and its role in human health and chronic diseases. Canadian Medical Association Journal, 2000, v.163, n.6, p. 739-44.

ANGELO, P. M.; JORGE, N. Compostos fenólicos em alimentos - Uma breve revisão. Revista do Instituto Adolfo Lutz, São Paulo, 66(1): 1-9. 2007.

ARABBI, P. R. Alimentos Funcionais - aspectos funcionais. Nutrire, 2001, v.21 p. 87-102.

ASSIS, A. M. O.; BARRETO, M. L. Suplementação com vitamina A: impacto na morbidade e efeitos adversos. Revista Brasileira de Epidemiologia, 2002, v.5, n.1, p.84-92.
BEER, D. JOUBERT, E.; GELDERBLOM, W. C.; MANLEY, M. Antioxidant activity of South African red and white cultivar wines: Free radical scavenging. Journal of Agricultural and Food Chemistry, 2003, v. 51, p.902-909.

BENDICH, A.; OLSON, J. A. Biological actions of carotenoids. FASEB Journal, 1989, v. 3, p.1927-1932.

BIANCHI, M. L. P.; ANTUNES, L. M. G. Radicais livres e os principais antioxidantes da dieta. Revista de Nutrição, 1999, v. 12, n.2, p. 123-130.

BRASIL, Ministério da Saúde, Agência Nacional de Vigilância Sanitária. Alimentos com alegações de propriedades funcionais e ou de saúde, novos alimentos/ ingredientes, substancias bioativas e probióticos: lista de alegações de propriedades funcional aprovadas, 2008. Disponível em: <http://www.anvisa.gov.br/alimentos/comissoes/tecno_lista_a lega.html>. Acesso em: 20 out. 2014.

BONI, A.; PUGLIESE, C.; CLÁUDIO, C. C.; PATIN, R. V.; OLIVEIRA, F. L. C.. Vitaminas antioxidantes e prevenção da arteriosclerose na infância. Revista Paulista de Pediatria, v.28, n.4, p.373-380, 2010.

COLli, C.; SARDINHA, F.; FILISETTI, T. M. C. C. Alimentos Funcionais. In: Cuppari, L. Guias de Medicina Ambulatorial e Hospitalar - Nutrição - Nutrição Clínica no

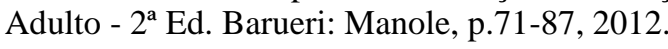

DAMODARAN, S.; PARKIN, K.; FENNEMA, O. R. Fennema's food chemistry. 4. ed. Boca Raton: CRC Press, 2008. 1144 p.

DELMAS, D.; JANNIN, B.; LATRUFFE, N.. Resveratrol: Preventing properties against vascular alterations and ageing. Mol. Nutr. Food Res., v. 49, p. 377-395. 2005.

EDGE, R.; MCGARVEY, D. J.; TRUSCOTT, T. G. The carotenoids as anti-oxidants - a review. Journal of Phitochemistry and Phitobiology, v. 41, p. 189-200. 1997.

FERRARONI, M. LA VECCHIA, C.; D'AVANZO, B.; NEGRI, E.; FRANCESCHI, S.; DECARLI, A. Selected micro-nutrient intake and the risk of colorectal cancer. Brazilian Journal of Cancer, v. 70, p. 1150-1155. 1994.

FERREIRA, A. L. A; MATSUBARA, L. S. Radicais livres: conceitos, doenças relacionadas, sistema de defesa e estresse oxidativo. Revista da Associação Médica Brasileira, vol.43 n.1 São Paulo Jan./Mar. 1997.

FRANCESCHINI, S. C. C.; PRIORE, S. E.; EUCLYDES, M. P. Necessidades e recomendações de nutrientes. In: Cuppari, L. Guias de Medicina Ambulatorial e Hospitalar - Nutrição Nutrição Clínica no Adulto - 2a Ed., p.3-32, 2012.

GALLAGHER, M. L. Ingestão: Os nutrientes e seu metabolismo. In: Krause: alimentos, nutrição e dietoterapia. Rio de Janeiro: Elsevier, 2012, p.33-128. 
GUINAZI M. Tocoferóis e tocotrienois em hortaliças, ovos e óleos vegetais utilizados em restaurantes comerciais [dissertação]. Viçosa (MG): UFV; 2004.

HAYEK, T.; FUHRMAN, B.; VAYA, J.; ROSENBLAT, M.; BELINKY, P.; COLEMAN, R.; ELIS, A.; AVIRAM, M. Reduced Progression of Atherosclerosis in Apolipoprotein EDeficient Mice Following Consumption of Red Wine, or Its Polyphenols Quercetin or Catechin, Is Associated With Reduced Susceptibility of LDL to Oxidation and Aggregation. Arteriosclerosis Thrombosis and Vascular Biology, v.17, p. 2744-2752. 1997.

KING, A, YOUNG, G. Characteristics and occurrence of phenolic phytochemicals. Journal of the American Dietetic Association, 50 (2):213-8. 1999.

KRINSKY, N. I. The biological properties of carotenoids. Pure Appl. Chem., v. 66, p. 1003-1010. 1994.

KUCUK, O.; SARKAR, F. H.; DJURIC, Z.; SAKR, W.; POLLAK, M. N.; KHACHIK, F.; BANERJEE, M.; BERTRAM, J. S.; WOOD, D. P. JR. Effects of lycopene supplementation in patients with localized prostate cancer. Exp. Biol. Med., v. 227, p. 881-885. 2002.

MARINOVA, D.; RIBAROVA, F. HPLC determination of carotenoids in Bulgarian berries. Journal of Food Composition and Analysis, v. 20, n. 5, p. 370-374. 2007.

MORAES, F. P.; COLLA, L. M. Alimentos funcionais e nutrecêuticos: Definiçõos, legislação e benefícios à saúde. Revista Eletrônica de Farmácia, Vol 3 (2), 99-112. 2006.

MOREIRA, A. V. B. Vitaminas. In: Tratado de alimentação, nutrição e dietoterapia. São Paulo: Roca, p.77-104, 2007.

OLIVEIRA, D. S.; AQUINO, P. P.; RIBEIRO, S. M. R.; PROENÇA, R. P. C.; PINHEIRO-SANT'ANA, H. M. Vitamina C, carotenoides, fenólicos totais e atividade antioxidante de goiaba, manga e mamão procedentes da Ceasa do Estado de Minas Gerais. Acta Scientiarum Health Sciences, v. 33, n. 1, p. 89-98, 2011.

PIMENTEL, C. V. M. B.; FRANCKI, V. M.; GOLLÜCKE, A. P. B. Alimentos funcionais: introdução as principais substâncias bioativas em alimentos. São Paulo: Ed. Varela, p95, 2005.

RAO, A. V.; AGARWAL, S. Role of lycopene as antioxidant carotenoid in the prevention of chronic diseases: A review. Nutr. Res., v. 19, p. 305-323, 1999.

RAVEN, P. H.; EVERT, R. F.; EICHHORN, S. E. Biologia vegetal. $6^{a}$ ed. Rio de Janeiro: Guanabara Koogan, 2001. 906 p.

RIOS, A. O.; ANTUNES; L. M. G.; BIANCHI, M. de L. P. Proteção de carotenóides contra radicais livres gerados no tratamento de câncer com cisplatina. Alimentação Nutrição, Araraquara v.20, n.2, p. 343-350, jan./mar. 2009.
SCOLASTICI, C.; LIMA, R. O.; BARBISAN, L. F.; FERREIRA, A. L.; RIBEIRO, D. A.; SALVADORI, D. M. Lycopene activity against chemically induced DNA damage in Chinese hamster ovary cells. Toxicology in Vitro, Roma, v. 21, p. 840-845. 2007.

SHAMI, N. J. I.; MOREIRA, E. A. M. Licopeno como agente antioxidante. Revista de Nutrição, 17(2):227-236, abr./jun. 2004.

SILVA, M. L. C.; COSTA, R. S.; SANTANA, A. DOS S.; KOBLITZ, M. G. B. Compostos fenólicos, carotenoides e atividade antioxidante em produtos vegetais. Semina: Ciências Agrárias, v. 31, n. 3, p. 669-682, jul./set. 2010.

SKEAFF, M. Vitamina C e E. In: Mann, J.; Truswell, S. Nutrição Humana - vol. 1, $3^{\mathrm{a}}$ Ed. Rio de Janeiro: Guanabara Koogan, p.220-232, 2009.

SOARES, S. E. Ácidos fenólicos como antioxidantes. Revista de Nutrição, v.15, n.1, p.71-81, 2002.

SOUZA, P. H. M.; SOUZA NETO, M. H.; MAIA, G. A. Componentes funcionais nos alimentos. Boletim da SBCTA, v. 37, n. 2, p. 127-135. 2003.

STRINGHETA, P. C.; OLIVEIRA, T. T.; GOMES, R. C.; AMARAL, M. P. H.; CARVALHO, A. F.; VILELA, M. A. P. Políticas de saúde e alegações funcionais e de saúde para alimentos no Brasil. Revista Brasileira de Ciências farmacêuticas. v. 43, p 181-194, 2007.

VALDUGA, E.; TATSCH, P. O.; TIGGEMANN, L.; TREICHEL, H.; TONIAZZO, G.; ZENI, J.; DI LUCCIO, M.; FÚRIGO JÚNIOR, A. Produção de carotenoides: microrganismos como fonte de pigmentos naturais. Quím. Nova, v. 32, n. 9, p. 2429-2436, out. 2009. 